\title{
New vistas for marketing strategy: digital, data-rich, and developing market $\left(D^{3}\right)$ environments
}

\author{
Shrihari Sridhar ${ }^{1} \cdot$ Eric Fang ${ }^{2,3}$ \\ Published online: 29 October 2019 \\ (C) Academy of Marketing Science 2019
}

\begin{abstract}
The last decade has seen marketing strategy evolve rapidly in three major directions, which can be summarized in three Ds: Digital, Data-Rich, and Developing Markets. The first D refers to "digital"; digital marketing strategy deals with firms' judicious use of digital resources to create differentiated and sustainable value for customers. The second D is "data-rich"; digital marketing has made available to researchers unprecedented data on firm and customer behavior. The third D is "developing markets"; the issue of marketing strategy in a digital and data-rich context is particularly relevant in developing markets such as BRIC (Brazil, Russia, India, and China) countries. This article formally define the scopes of the three Ds, identify opportunities associated with three Ds, and highlights the work published in these areas that will hopefully trigger more research work in $\mathrm{D}^{3}$ environments.
\end{abstract}

Marketing strategy consists of firms' decisions and actions focused on creating value for stakeholders by building sustainable differential advantage relative to competitors (Morgan et al. 2019; Varadarajan 2010; Palmatier and Sridhar 2017). For several decades, scholars of marketing strategy have expanded the domain and the impact of the field by identifying new substantive problems (Lehmann et al. 2011; Moorman 2016) and discovering rigorous ways to solve these problems (e.g., Green and Srinivasan 1990; Grewal 2017). The last decade has seen marketing strategy evolve rapidly in three major directions, which can be summarized in three Ds: Digital, Data-Rich, and Developing Markets. The purpose of this special issue is to formally define the scope of the three Ds, identify opportunities associated with three Ds,

Shrihari Sridhar

ssridhar@mays.tamu.edu

Eric Fang

erfang@illinois.edu

1 Mays Business School, Texas A\&M University, 201L Wehner Building, College Station, TX 77843, USA

2 China Europe International Business School (CEIBS), Shanghai, China

3 Gies College of Business, University of Illinois, 83 Wohlers Hall, Champaign, IL 61820, USA and highlight the work published in this special issue that will hopefully trigger more research work in $\mathrm{D}^{3}$ environments.

The first D refers to "digital"; digital marketing strategy deals with firms' judicious use of digital resources (e.g., web analytics, social media and mobile platforms, keyword choice) to create differentiated and sustainable value for customers (Bharadwaj et al. 2013). Digital marketing strategy has fundamentally changed the marketing landscape as it not only enriches the tools that firms employ in customer relationships but also empowers customers by providing them opportunities to interact with firms, which was heretofore impossible. The second D is "data-rich"; digital marketing has made available to researchers unprecedented data on firm and customer behavior. Data include structured data, such as numerical data on consumer purchasing behaviors; firms' digital marketing interventions; and unstructured data, such as text, audio, or even video content from consumers and firms. With the advent of the digital era, marketers are better able to harness the data to acquire, expand and retain more customers (Wedel and Kannan 2016). The third D is "developing markets"; the issue of marketing strategy in a digital and data-rich context is particularly relevant in developing markets such as BRIC (Brazil, Russia, India, and China) countries. As Sheth (2011) argues, marketing is a context-driven discipline that has historically adapted to developing constructs and schools of thought around the evolving marketplace. Developing markets have been the growth engines of the world economy in recent years, and they continue to gain share of the world economy through renowned e-commerce giants such as Alibaba and Baidu. 
Developing markets are also fundamentally different from developed markets in market, governance, competition, resources and infrastructure constraints (see Sheth (2011) for a detailed review). The growing importance of developing markets in the world economy suggests that understanding the practice of marketing in developing markets is critical to firm success. The broad topic for this special issue, $\mathrm{D}^{3}$ environments, is contoured by a focus on research that internalizes this growing world vista. Figure 1 organizes the overall structure of the editorial by describing the salient features of digital, data-rich, and developing environments. We describe these three Ds in more detail next.

\section{Digital $\left(D^{1}\right)$ environments}

The growth of digital marketing strategy is inextricably linked to the growth of digital technology, as well as to organizations' needs to incorporate this technological advance in their strategic planning. As Goldfarb and Tucker (2019) argue, digital technology, or the representation of information in bits, has fundamentally lowered fives kinds of costs in the marketplace (see Fig. 1):

- Search costs or the costs of looking for information. Digital technology has made it possible for both individual agents and organizations to gather information at a faster rate. For example, customers can, at no cost, obtain information on products, while organizations are able to gather information on competitors' prices, at no cost, on thirdparty websites.

- Replication costs or the cost of producing goods. Digital technology has created digital goods that have a marginal cost of zero, as against all physical goods, which have non-zero cost. For example, software developers can replicate their code with no direct cost through open-source platforms, and rivals can obtain this code at no cost from open source platforms.

- Transportation costs or the cost of transporting information and goods from one place to another. Again, digital technology has no physical distance as a deterrent to obtaining information, goods (e.g., products), services (e.g., banking) and expertise (e.g., workforce).

- Tracking costs or the cost of obtaining stage-by-stage information about the production or consumption of goods or services. With reduced to zero tracking costs, the floodgates have opened up for industries such as customization (e.g., computing equipment), personalization (e.g., apparel), and customer engagement during the customer journey (e.g., vacations, pizza delivery).

- Verification costs or the costs of validating the identity and reputation of an agent. Digital technology has dramatically lowered the cost of verifying product quality through the emergence of online reviews, and also lowered friction and asymmetry to lack of verifiable information in the customer journey.

Buoyed by the exponential growth in digital technology, companies need an organizational strategy to leverage digital resources to create differential value, almost as a cost of competing. Digital strategies consist of four parts: (1) a scope, which defines the boundary of settings that the digital strategy applies to, (2) the scale, which captures the production, supply and demand boundaries of the strategy, (3) the speed, which captures the timing of strategic decisions surrounding value creation and capture, and (4) the actual sources of business value creation and capture in the organization's business model (Bharadwaj et al. 2013).

The marketing function is poised to gain even more importance due to the growth of digital technology and formalization of organizations' digital strategies. After all, marketing's role in the organization is to help define, own, and manage the organization's customer interface. Indeed, results from the CMO survey show that organizations now derive $12.2 \%$ of sales through digital channels, ${ }^{1}$ and the average growth in digital marketing spend (about 12\%-13\%) is almost 6 to 8 times more than in traditional marketing spend. ${ }^{2}$ Yet, firms continue to lack overarching frameworks to (1) devise digital marketing strategies with a clear objective to create and capture value from customers, and (2) align with existing marketing strategies and create synergistic value propositions for the customer. Given this combination of immense opportunity in the marketplace and lack of knowledge among managers, the marketing research community can help fill these opportunities and contribute more to digital marketing strategy.

Extant digital marketing research can broadly be classified as studying three main issues that we believe can be tied back to the foundational differences of digital technology itself. The first stream of research studies how customers' decisions and actions have changed due to access to a new digital environment, i.e., technologies and products (e.g., search engines, review websites, social media websites, matching platforms, auctions). We have witnessed several new phenomenological changes in customer behavior due to digital technology. For example, while Seiler (2013) showed that customers do not search for items in around $70 \%$ of their shopping trips due to high search costs, Bronnenberg et al. (2016) show that on average customers conduct 14 online searches for a camera in the 2-week period before purchase. This is a classic illustration of how the reduction of search costs enabled by digital technologies transforms consumer behavior by changing their

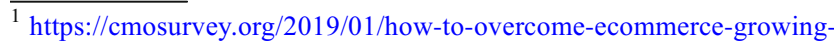
pains/

${ }^{2}$ https://cmosurvey.org/wp-content/uploads/sites/15/2018/08/The_CMO_ Survey-Highlights_and_Insights_Report-Aug-2018.pdf
} 
information structure within the marketplace. Indeed, they show that a 1-min increase in smartphone usage decreases computer usage time by $0.14 \mathrm{~min}$ (significant at $1 \%$ ), suggesting that the change of customer behavior has telling financial implications for organizations. The consumption of digital technology could also lead to heretofore understudied outcomes. For example, Chen et al. (2018) show that a \$1-million increase in school district provided internet access (SDIAS) is associated with an improvement of 9 out of 10 academic performance indicators (with effect sizes ranging from $1 \%$ to $10 \%$ of a standard deviation), which amounts to an increase of cumulative present student income value of $\$ 1.2$ million to $\$ 2.5$ million for a school district.

However, it is also associated with a $7 \%$ increase in Part II offense-related school disciplinary problems, amounting to a yearly cost of $\$ 38,700$ to $\$ 80,160$ for a school district. This highlights the need for future research to look more holistically into the changes in consumption brought about by the evolution of digital technology. Indeed, in a recent Special Issue on Consumer Journeys in the Journal of the Academy of Marketing Science, editors Hamilton and Price note the importance of continuing to understand "holistically how people move into and out of consumer roles and customer journeys," a research agenda that is in all likelihood inextricably linked to research in digital environments.

The second stream of research studies focuses on how organizations' decisions and actions have changed due to the evolution of digital technology. From a product standpoint, the advent of digital technologies means that organizations can augment their capabilities with new offerings, be it through new products (e.g., books, newspapers), services (e.g., subscription services for entertainment, food, travel) or the creation of matching platforms that bring buyers and sellers together. This has led to new research questions pertaining to the design of digital products and services, and questions about the value of multichannel shoppers. Given the low (or even zero) replication costs of digital technology, its growth has led to creative price bundling strategies among marketers, and spawned an array of questions about the optimality of freemium and subscription-based strategies. It has also led to a proliferation of research on product portfolio questions such as the cannibalization of traditional and digital products. The low tracking and verification costs of digital technology have meant that organizations can add new sources of revenue around the personalization of customer promotions. For example, Chung et al. (2009) developed a personalized system for online music that took into account a customer's past behavior while creating the promotion. Fong et al. (2016) present a methodology to target customers with e-book promotions while taking into account individual-level heterogeneity of book preferences among customers. Finally, the lowering of transportation costs due to digital technology has spawned tremendous research on the ability of online channels to reach more customers and increase firm value (Geyskens et al. 2002), as well as effectively created the domain for omni-channel marketing (Verhoef et al. 2015).

The third stream of research focuses on how digital marketing contributes to firm and marketplace outcomes, broadly classified into financial outcomes (e.g., sales, margins, stock price, EBITDA) and non-financial outcomes (e.g., customer satisfaction, loyalty, brand equity). Research in this area focuses on finding a link between the introduction of new digital technologies and firms' outcomes. For example, Gill et al. (2017) study firms' returns on digital-engagement initiatives, which are meant to facilitate firm-customer interactions or interactions among customers, with the primary goal of fostering emotional and psychological bonds between customers and the firm. They implement a methodological framework to investigate a business-to-business mobile app that a tool manufacturer provides for free to engage its buyers and they find that the app increased the manufacturer's annual sales revenues by $19.11 \%$ to $22.79 \%$. Thus, digital marketing, in this instance, contributed positive and incremental value to the organization. Accordingly, research in this area also focuses on the correct design of digital technology interfaces to increase firm outcome. Bleier et al. (2019) conduct 16 experiments to study how 13 unique design elements shape four dimensions of the online customer experience (informativeness, entertainment, social presence, and sensory appeal) and thus influence purchase. The results provide managers with clear strategic guidance on how to build effective web pages. Finally, research has also focused on providing guidance on the correct amount of digital spending required to maximize firm outcomes. Sridhar et al. (2016) find that while every one of national, regional, and online advertising have a positive and significant main effect on firm performance, each advertising vehicle weakens the effectiveness of the other two advertising vehicles respectively. Thus, all three media vehicles contribute to net increases in performance, but need to be strategically integrated for them to maximize combined effectiveness. We expect research in digital marketing strategy to continue to grow further in these dimensions, poised by increased future spending in digital spend.

\section{Digital, data-rich $\left(D^{2}\right)$ environments}

Early digital marketing research focused on how firms could leverage the digital distribution channel. Even as new technologies and channels become ubiquitous, firms face the complex decision of whether to use them (Lee and Grewal 2004), and when they use them, and are unsure about whether they pay off. The provision of new digital channels could potentially generate more sales for firms (Geyskens et al. 2002), but also create 
sustained competitive advantage. Adding new digital channels may not pay off. Firms may not possess the resources, both tangible and intangible (e.g., skills and know-how, processes and routines), to generate economic rents. Moreover, the net payoff of a new digital channel depends on its performance effects on the entire channel system. New digital channels could create negative spillovers on existing channels through concerns like cannibalization, and thus generate an overall negative payoff for the firm, even if the firm benefits from one of the new channels. This stream of research (from the early 2000s to about 2014-15) launched a series of investigations to compare how firms, consumers, and competitors behave differently in digital versus off-line markets. This stream of research included questions such as: how to design responsive digital and mobile communication strategy; how to design, measure, and implement product portfolio strategy in the presence of digital and mobile channels; and how consumers fundamentally change their attitude, knowledge structure, and behavior in the presence of digital technology.

In the last 6 to 7 years, marketing scholars have embraced the inherently data-rich nature of digital environments (or the D2 environment). The D2 environment often has to grapple with substantive and methodological problems that are not traditional in nature, largely because of having to contend with new forms of data environments, sometimes referred to as "big" data environments. These data environments are characterized by five new facets that marketing researchers should take into account (e.g., Lam et al. 2017): (1) volume, which refers to these massive amounts of data that allow firms to go beyond historical data and outside the focal customer touch points (e.g., stores and service stations) to achieve a more comprehensive view of the customer, (2) velocity, or the speed at which data are generated, (3) variety of the new forms of data (text, speech, video) that challenge the traditional tabular format (variables in columns, data in rows) that marketing researchers are used to, (4) veracity, or the extent of consistency, accuracy, and usefulness of data for functional use, and (5) value, or the ability to generate actionable and academically worthy insights. As Lam et al. (2017) note, these data environments challenge firms' data acquisition, assimilation, transformation, and application capacities. As Lazer and Radford (2017) elegantly summarize, the data-richness from digital environments mainly comes from three sources (see Fig. 1):

- Digital life. The emergence of digital technology first gives us access to customers' and firms' digital lives. Data from platforms like Twitter and Facebook provide digital access to customer behaviors that would otherwise be observed in their off-line lives, and also provide researchers an opportunity to observe how firms harvest such data to generate economic value (through selling customer attention, or capturing it). As Lazer and Radford (2017) state, data from the digital lives of firms and consumers serve as generalizable microcosms of society.

- Digital traces. Digital and data-rich $\left(\mathrm{D}^{2}\right)$ environments give rise to digital traces, or steady output of records that chronicle actions taken by customers, firms, or third-party organizations. These digital traces, when concatenated in suitable ways, allow us to connect the knowledge from several consumers/firms/third parties. One way to connect this information is chronologically, through the use of time stamps. A second way is through the formation of networks or strength of association. A third way is to collate information geographically, and a final way is to piece together a customer (or firm's) journey through a mix of time, space, and geography across digital platforms.

- Digitalized life. Perhaps the most recent (and hence the least exploited) aspect of $\mathrm{D}^{2}$ environments is digitalized life, or the capture of intrinsically non-digital life in digital form through the use of technology. This could include capturing conversations among consumers (through Bluetooth devices), customer reactions to off-line situations (e.g., in-store promotions) through digital cameras, or constant streaming and recording of customer and firm behavior through the growth and efficiency of cloud storage (e.g., smartphone data). As technologies evolve, the ways of capturing and collating digitalized life from essentially non-digital sources has exponentially increased.

The prevalence of data from digital life, digital traces, and digitalized life in $\mathrm{D}^{2}$ environments opens up new substantive possibilities for research in $\mathrm{D}^{2}$ environments. Indeed, recent research from the Journal of the Academy of Marketing Science has already found intriguing results. Sciandra et al. (2019) show that consumers' shopping-unrelated mobile phone use leads to inaccurate in-store shopping plans and an increase in unplanned purchasing. Hildebrand and Schlager (2019) show that exposure to Facebook prior to a product configuration task enhances consumers' tendency to upgrade conventional products. Mills and Zamudio (2018) observe supermarket shoppers who use their smartphones to scan products in-store and find that a $\$ 0.50$ coupon can have a redemption probability as low as $30 \%$ and as high as $80 \%$, depending on the segment of mobile shopper targeted. Hanson and Yuan (2018) find that firms can benefit from online social couponing because customers who share coupons spend more and report greater purchase intentions than those who do not share coupons.

Researchers have also undertaken descriptive work using large data sets to better understand how digital life, digital traces, and digitalized life in $\mathrm{D}^{2}$ environments affect customer and firm behavior. Daurer et al. (2015) analyze search behavior of 2.5 million consumers for 1.8 million different products from a bar code-scanning app to find that while consumers search for more detailed information about 


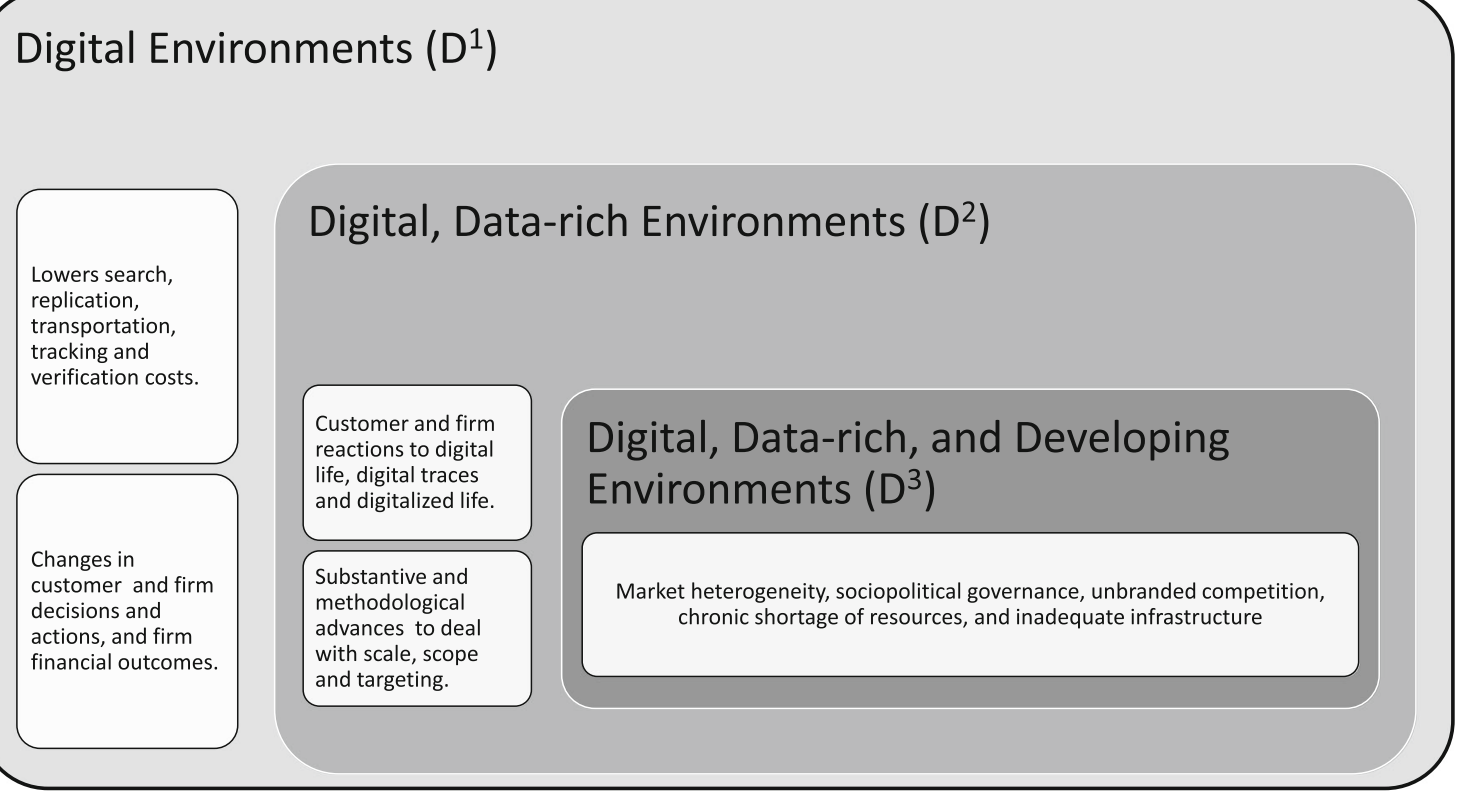

Fig. 1 Salient features of digital, data-rich, and developing environments

specific products, they rarely compare different competing products with the use of their smartphones. By contentcoding more than 100,000 unique messages engaging Facebook users, Lee et al. (2018) find that emotional content increases engagement with a message. Informative content, on the other hand, reduces engagement when used in isolation, but increases engagement when provided in combination with persuasive attributes. As $\mathrm{D}^{2}$ environments grow in popularity, one would expect to see more descriptive research focused on explaining digital life, digital traces, and digitalized life.

Finally, it is almost a requisite that we will need new methodological and conceptual advances to fully exploit the richness of $\mathrm{D}^{2}$ environments and their ramifications. We see at least three avenues for methodological advances. First, the sheer scale of $\mathrm{D}^{2}$ environments will entail newer approaches and algorithms to extract managerial and statistical insights from the data. For example, traditional methods of monitoring and validating perceptions using surveys become untenable when we gather millions of observations about a firm on social media. Culotta and Cutler (2016) develop a fully automated method for inferring attribute-specific brand perception ratings on Twitter (Social Perception Score). Ringel and Skiera (2016) develop a new method to feature-reduce and comprehensively visualize hundreds of competitive market structures in the LED TV market. Second, the scope of data in $\mathrm{D}^{2}$ environments will necessitate new methods in text-processing, audio-processing, and video-processing. Balducci and Marinova (2018) offer a rich an integrative framework that combines both theoretical and computational advances that are necessary to exploit unstructured text, voice, or video data, which are pervasive in $\mathrm{D}^{2}$ environments. Third, the availability of data at the individual level provides a great opportunity to establish a new methodology to obtain individual-level treatment effects, which would not only advance the state of theory in $\mathrm{D}^{2}$ environments by embellishing our understanding of how consumers react to marketing interventions, but also help extract more insight from field experiments in $\mathrm{D}^{2}$ environments. For example, Chen et al. (2019a, b) use observable patient characteristics (race, gender, health status, and visit history) to explain heterogeneity in the marketing effectiveness of cancer outreach and provide a road map for implementing tailored interventions. Their patientlevel economic cost-benefit analysis could be used as a template by other healthcare organizations in justifying the economic return on cancer outreach investment.

\section{Digital, data-rich, and developing $\left(D^{3}\right)$ environments}

The growth of $\mathrm{D}^{2}$ markets in digital marketing strategy is inextricably linked to the emergence of developing markets and organizations' imperatives to tap into these opportunities. Developing (or emerging) environments are on track to have the same fiscal transparency, focus on production, regulatory bodies and exchanges, and acceptance of outside investment as the world's most developed environments (Sraders 2018). Today, about $80 \%$ of the world's economy is comprised of developing economies, led by China, India and Russia 
(Sraders 2018). A recent World Bank report forecasts that the $\$ 75$ trillion world economy will expand by another $\$ 6.5$ trillion in the next 3 years, with at least $50 \%$ of the growth coming from developing economies. ${ }^{3}$ However, as Sheth (2011) notes in an influential piece, developing economies involve idiosyncratic challenges for marketing practitioners as well as researchers (see Fig. 1). These include:

- Market heterogeneity. Given that they are local, fragmented, low-scale, and mostly served by ownermanaged small enterprises, developing economies have large variance relative to the mean across almost all products and services.

- Sociopolitical governance. Developing environments are heavily influenced by sociopolitical institutions such as religion, government, business groups, nongovernmental organizations (NGOs), and local community. In some cases, these environments are more influenced by sociopolitical institutions than traditional market competition.

- Unbranded competition. A large portion (about 60\%) of consumption in developing environments comes from unbranded products and services, either because branded products are still not available in rural areas, and/or because a household is both a consumption and production unit in many cases.

- Chronic shortage of resources. A quintessential feature of developing environments is a chronic shortage of resources in production, exchange, and consumption, which generally leads to inconsistency and nonreplicable production processes, and in turn, diseconomies of scale.

- Inadequate infrastructure. Related, developing environments are also faced with the problem of inadequate infrastructure (e.g., roads, electricity, storage, logistics) that makes exchange models such as those in developed environments almost untenable in some cases.

Of relevance to this Special Issue is the notion that the emergence of $\mathrm{D}^{2}$ environments in developing countries has catapulted their growth in the last decade. A review article by Atsmon et al. (2012) clearly underscores the importance of $\mathrm{D}^{2}$ environments to the growth of developing economies as well to firms' global market strategies. It highlights that the majority of consumers in developing environments are in their 20 s and 30 s, with growing incomes, and are Internet users. Some important trends highlighted include the notion that (1) more than half the global Internet users are in developing environments, (2) the highest penetration of social media is in these regions, and (3) the emergence of e-commerce and mobile payments has helped developing environments leapfrog developed-market norms and is creating indigenous market giants such as Baidu and M-Pesa that leverage $\mathrm{D}^{2}$

\footnotetext{
${ }^{3}$ https://www.visualcapitalist.com/chart-global-growth-happening/
}

environments. A detailed report by the Pew Research Center in $2015^{4}$ highlighted some important consumption trends in $\mathrm{D}^{3}$ environments. These include:

- A total of $24 \%$ of customers in emerging and developing countries own Internet-capable smartphones. In only two of the countries polled do more than half the customers have a smartphone $-58 \%$ in Chile and 55\% in China, on par with the $58 \%$ of Americans who report owning this kind of device.

- Younger users are much more likely to say they access the Internet daily, compared with older people. For example, 95\% of Internet users in Lebanon under 35 say they access the Internet daily, while only $67 \%$ of those over 34 say the same.

- A median of $82 \%$ use their Internet connections to access social networking sites such as Facebook, Twitter, and other country-specific platforms.

- A median of $64 \%$ across the 32 nations surveyed say that increasing Internet use has a good influence on education, with only $18 \%$ saying it has a bad influence. In general, across many countries, young people (18-34 years old) are much more likely to say that the Internet has a good influence, as compared with older people (ages 35-plus).

Even amid such a large opportunity there exists scant research in $\mathrm{D}^{3}$ environments, and the hope with this Special Issue is to trigger more research work.

\section{Overview of the $D^{3}$ articles in this issue}

This Special Issue brings together a set of 10 empirical articles from across the broad topic of $\mathrm{D}^{3}$ environments. The 10 papers were chosen from a set of 58 competitive submissions, indicating high interest in the topic. The submissions also came in on the back of a successful Thought Leaders' Conference on the same topic in Beijing, China, from June 2 to 4, 2017, hosted by the University of International Business and Economics (UIBE), which attracted over 100 submissions, and over 500 participants. We are grateful to the many authors, reviewers, and conference participants who helped bring this Issue to fruition, along with the vision, energy, and resolve of the editors Robert Palmatier and John Hulland.

Demonstrating the role of user characteristics in the process of information diffusion on social media platforms, work by Chen and colleagues (Chen et al. 2019a, b) shows that diffusers (i.e., users who do not generate new content but spread

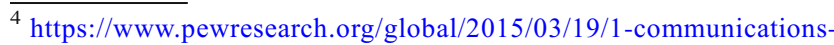
technology-in-emerging-and-developing-nations/
} 
content created by other users) are more likely than posters to repost the content when they are repeatedly exposed to the same piece of information in a dense network. They supplement the proprietary data of user behavior from a social networking site with a user survey and suggest that the (differential) reposting behaviors are driven by their need for uniqueness. Complementing this work, Wang and colleagues (Wang et al. 2019a) identify the systematic differences between hub (i.e., those with a large number of ties to other users) and non-hub users with respect to user type, follower type, and user-follower relationships. They further show that the relative effectiveness of hub users versus non-hub users is weakened as the content involves high emotionality or personal relevance to followers' lives, and as there is a lower number of synchronistic followers, or when their activity level is lower. Both studies shed light on how to unlock the power of heretofore neglected social media users, i.e., diffusers and non-hub users.

Content strategy has become a prevalent marketing practice in online markets, with an objective of engaging users and creating economic value for firms. Chang and colleagues (Chang et al. 2019) examine the impact of matching narrative-person (first-person vs. third-person) in the ads with brand image type (warmth vs. competence) on one's liking intention in the context of WeChat moment ads. They find that first-person (thirdperson) narration alongside warm (competent) brand images is more effective in enhancing the liking intention through an increase in users' motivation of social belonging (self-enhancement) and that these matching effects are more pronounced among high self-monitoring users. In a similar vein, Xiang and colleagues (Xiang et al. 2019) find that crowdfunding project pitches that focus on informational (emotional) appeal is associated with a larger number of consumer (investment) backers than with investment (consumer) backers. For project creators, this trade-off highlights the need to manage the level of backer's decision control, the project's social orientation, and tangibility of the reward as boundary conditions.

B2B firms in emerging markets strive to leverage external resources to manage challenges such as dependence disadvantage in channel relationships. Dong and colleagues (Dong et al. 2019) examine how the network embeddedness of the more-dependent (less-dependent) partner affects relationshipspecific investments (RSIs) of the less-dependent (moredependent) partner and their own channel performance. They find that while the more-dependent partner's network embeddedness elicits the less-dependent partner's RSIs, which in turn improves the more-dependent partner's profitability, the effects are much weaker for the less-dependent partner. Moreover, they suggest that when the dependence asymmetry is greater, the effect of the more-dependent partner's business (government) network embeddedness on the less-dependent partner's RSIs is attenuated (strengthened).

Another challenge for B2B firms in emerging markets is how to construct a profitable digital marketing investment portfolio. Vieira and colleagues (Vieira et al. 2019) study the impact of digital communications portfolio that involves firminitiated (e.g., sponsored advertising) and market-initiated (e.g., user-generated content) communications on sales and customer acquisition. They uncover the most effective pattern in increasing firm performance in the following order: owned media, digital inbound marketing, earned social media, and organic search, suggesting an especially important role of owned media and digital inbound marketing in influencing both customer acquisition and sales.

Work by Wang and colleagues (Wang et al. 2019b) examines whether and why the inclusion of a home country name in a stock name (i.e., home-name stock) affects a firm's stock returns and individual investor behavior in the context of Chinese stock market. Their secondary data analysis shows that home-name stocks significantly outperform non-homename stocks, and additional experiments further suggest that individual investors indeed have a higher investment intention on home-name stocks due to a stronger psychological identification with the firm.

Zou and Liu (2019) study the role of nutrition information in influencing online food sales. They show the presence of nutrition information is positively associated with food sales. This positive effect is more pronounced for (a) sellers with a higher reputation, and (b) healthy food. Their eye-tracking experiment further suggests that nutrition information is a helpful cue in food purchase decisions in online conditions.

Wang and colleagues (Wang et al. 2019c) examine the relative effectiveness of keyword advertising in an online versus mobile channel. Their field studies and experiments show that while a paid keyword in a mobile channel can increase direct sales more than it could in an online channel, it decreases indirect sales more than it does in an online channel. Moreover, they demonstrate that these relationships vary by keyword characteristics: while keyword cost weakens the positive relationship between mobile keyword advertising and direct sales, a combination of keyword specificity and keyword cost weaken the negative relationship between mobile keyword advertising and indirect sales.

Finally, building on a two-dimensional view of technological innovation (i.e., novelty and meaningfulness), Zou and colleagues (Zou et al. 2019) examine whether and how experimental learning and adaptive learning contribute to each dimension of technological innovation, and whether technological innovation contributes to shareholder value. Combining firm-level secondary data with a survey from executives of high-tech firms, they show that whereas adaptive learning increases (decreases) meaningfulness (novelty), experimental 
learning decreases meaningfulness but enhances novelty only when a firm has sufficient unabsorbed slack. Moreover, they show that meaningfulness increases a firm's shareholder value both independently as well as jointly in conjunction with novelty.

\section{Conclusion}

To summarize, we propose that important strategic insights can be uncovered by moving from a focus on digital environments to digital, data-rich, and developing $\left(\mathrm{D}^{3}\right)$ environments, which contain not only a unique set of characteristics (as summarized in Fig. 1) but also represent a sector of the marketplace that is exponentially growing. We hope that readers will enjoy reading the articles in the Special Issue and are hopeful that more exciting questions and solutions will emerge as we collectively surge forward into these new vistas.

\section{References}

Atsmon, Y., Child. P., Dobbs. R., \& Narasimhan. L. (2012). Winning the $\$ 30$ trillion decathlon: Going for gold in emerging markets. McKinsey report. [accessed at https://www.mckinsey.com/businessfunctions/strategy-and-corporate-finance/our-insights/winning-the30-trillion-decathlon-going-for-gold-in-emerging-markets]. Accessed July 2019.

Balducci, B., \& Marinova, D. (2018). Unstructured data in marketing. Journal of the Academy of Marketing Science, 46(4), 557-590.

Bharadwaj, A., El Sawy, O. A., Pavlou, P. A., \& Venkatraman, N. (2013). Digital business strategy: Toward a next generation of insights. MIS Quarterly, 37, 471-482.

Bleier, A., Harmeling, C. M., \& Palmatier, R. W. (2019). Creating effective online customer experiences. Journal of Marketing, 83(2), 98-119.

Bronnenberg, B. J., Kim, J. B., \& Mela, C. F. (2016). Zooming in on choice: How do consumers search for cameras online? Marketing Science, 35(5), 693-712.

Chang, Y., Li, Y., Yan, J., \& Kumar, V. (2019). Getting more likes: The impact of narrative person and brand image on customer brand interactions. Journal of the Academy of Marketing Science, 47(6). https://doi.org/10.1007/s11747-019-00632-2.

Chen, Y., Mittal, V., \& Sridhar, S. (2018). Broadband internet access: A double-edged sword for K-12 education? (p. 3162837). Mays business school research paper.

Chen, X., Li, Y., \& D., \& Zhou, Z. (2019a). Seeking the support of the silent majority: Are lurking users valuable to UGC platforms? Journal of the Academy of Marketing Science, 47(6). https://doi. org/10.1007/s11747-018-00624-8.

Chen, Y., Lee, J. Y., Sridhar, S., Mittal, V., Singal, A., \& McCallister, K. (2019b). Improving cancer outreach effectiveness through targeting and economic assessments: Insights from a randomized field experiment. Available at SSRN 3398456.

Chung, T. S., Rust, R. T., \& Wedel, M. (2009). My mobile music: An adaptive personalization system for digital audio players. Marketing Science, 28(1), 52-68.
Culotta, A., \& Cutler, J. (2016). Mining brand perceptions from twitter social networks. Marketing Science, 35(3), 343.

Daurer, S., Molitor, D., Spann, M., \& Manchanda, P. (2015). Consumer search behavior on the mobile internet: An empirical analysis. Available at SSRN.

Dong, M. C., Zeng, F. L., \& Su, C. (2019). Network embeddedness as a dependence-balancing mechanism in developing markets: Differential effects for channel partners with asymmetric dependences. Journal of the Academy of Marketing Science, 47(6). https://doi.org/10.1007/s11747-018-0614-5.

Fong, N. M., Zhang, Y., Luo, X., \& Wang, X. (2016). Targeted promotions and cross-category spillover effects (pp. 16-035). Fox School of Business Research paper.

Geyskens, I., Gielens, K., \& Dekimpe, M. G. (2002). The market valuation of Internet channel additions. Journal of Marketing, 66(2), 102 119.

Gill, M., Sridhar, S., \& Grewal, R. (2017). Return on engagement initiatives: A study of a business-to-business mobile app. Journal of Marketing, 81(4), 45-66.

Goldfarb, A., \& Tucker, C. (2019). Digital economics. Journal of Economic Literature, 57(1), 3-43.

Green, P. E., \& Srinivasan, V. (1990). Conjoint analysis in marketing research: New developments and directions. Journal of Marketing, $54(4), 3-19$.

Grewal, R. (2017). Journal of marketing research: Looking forward. Journal of Marketing Research, 54(1), 1-4.

Hanson, S., \& Yuan, H. (2018). Friends with benefits: Social coupons as a strategy to enhance customers' social empowerment. Journal of the Academy of Marketing Science, 46(4), 768-787.

Hildebrand, C., \& Schlager, T. (2019). Focusing on others before you shop: exposure to Facebook promotes conventional product configurations. Journal of the Academy of Marketing Science, 47(2), 291-307.

Lam, S. K., Sleep, S., Hennig-Thurau, T., Sridhar, S., \& Saboo, A. R. (2017). Leveraging frontline employees' small data and firm-level big data in frontline management: An absorptive capacity perspective. Journal of Service Research, 20(1), 12-28.

Lazer, D., \& Radford, J. (2017). Data ex machina: Introduction to big data. Annual Review of Sociology, 43, 19-39.

Lee, R. P., \& Grewal, R. (2004). Strategic responses to new technologies and their impact on firm performance. Journal of Marketing, 68(4), 157-171.

Lee, D., Hosanagar, K., \& Nair, H. S. (2018). Advertising content and consumer engagement on social media: Evidence from Facebook. Management Science, 64(11), 5105-5131.

Lehmann, D., McAlister, L., \& Staelin, R. (2011). Sophistication in research in marketing. Journal of Marketing, 75(4), 155-165.

Mills, P., \& Zamudio, C. (2018). Scanning for discounts: Examining the redemption of competing mobile coupons. Journal of the Academy of Marketing Science, 46(5), 964-982.

Moorman, C. (2016). Celebrating marketing's dirty word. Journal of the Academy of Marketing Science, 44(5), 562-564.

Morgan, N. A., Whitler, K. A., Feng, H., \& Chari, S. (2019). Research in marketing strategy, Research in marketing strategy. Journal of the Academy of Marketing Science, 47(1), 4-29.

Palmatier, R. W., \& Sridhar, S. (2017). Marketing strategy: Based on first principles and data analytics. Macmillan International Higher Education.

Ringel, D. M., \& Skiera, B. (2016). Visualizing asymmetric competition among more than 1,000 products using big search data. Marketing Science, 35(3), 511-553.

Sciandra, M. R., Inman, J. J., \& Stephen, A. T. (2019). Smart phones, bad calls? The influence of consumer mobile phone use, distraction, and phone dependence on adherence to shopping plans. Journal of the Academy of Marketing Science, 1-21. 
Seiler, S. (2013). The impact of search costs on consumer behavior: A dynamic approach. Quantitative Marketing and Economics, 11(2), 155-203.

Sheth, J. N. (2011). Impact of emerging markets on marketing: Rethinking existing perspectives and practices. Journal of Marketing, 75(4), 166-182.

Sraders, A. (2018). What are emerging markets? Characteristics and list in 2019. The street. (month and year?), [accessed at: https://www. thestreet.com/markets/emerging-markets/what-are-emergingmarkets-14819803]. Accessed July 2019.

Sridhar, S., Germann, F., Kang, C., \& Grewal, R. (2016). Relating online, regional, and national advertising to firm value. Journal of Marketing, 80(4), 39-55.

Varadarajan, R. (2010). Strategic marketing and marketing strategy: Conceptual domain, definition, fundamental issues and foundational premises. Journal of the Academy of Marketing Science, 38(2), 119140.

Verhoef, P. C., Kannan, P. K., \& Inman, J. J. (2015). From multichannel retailing to omni-channel retailing: Introduction to the special issue on multi-channel retailing. Journal of Retailing, 91(2), 174-181.

Vieira, V. A., Almeida, M. I. S., Agnihotri, R., Silva, N. S., \& Arunachalam, S. (2019). In pursuit of an effective B2B digital marketing strategy in an emerging market. Journal of the Academy of Marketing Science, 47(6). https://doi.org/10.1007/s11747-019-00687-1.

Wang, Q., Miao, F., Tayi, G. K., \& Xie, E. (2019a). What makes online content viral? The contingent effects of hub users versus non-hub users on social media platforms. Journal of the Academy of Marketing Science, 47(6). https://doi.org/10.1007/s11747-01900678-2.
Wang, H., Yuan, H., Li, X., \& Li, H. (2019b). The impact of psychological identification with home-name stocks on investor behavior: An empirical and experimental investigation. Journal of the Academy of Marketing Science, 47(6). https://doi.org/10.1007/s11747-01900677-3.

Wang, F., Zuo, Y., \& Wu, Y. (2019c). Mobile searching versus online search effects of paid search keywords on direct and indirect sales. Journal of the Academy of Marketing Science, 47(6). https://doi.org/ 10.1007/s11747-019-00649-7.

Wedel, M., \& Kannan, P. K. (2016). Marketing analytics for data-rich environments. Journal of Marketing, 80(6), 97-121.

Xiang, D., Zhang, L., Tao, Q., Wang, Y., \& Ma, S. (2019). Informational or emotional appeals in crowdfunding message strategy: An empirical investigation of backers' support decisions. Journal of the Academy of Marketing Science, 47(6). https://doi.org/10.1007/ s11747-019-00638-w.

Zou, P., \& Liu, J. (2019). How nutrition information influences online food sales. Journal of the Academy of Marketing Science, 47(6). https://doi.org/10.1007/s11747-019-00668-4.

Zou, L., Fisher, G., \& Yang, Z. (2019). Organizational learning and technological innovation: The distinct dimensions of novelty and meaningfulness that impact firm performance. Journal of the Academy of Marketing Science, 47(6). https://doi.org/10.1007/s11747-01900633-1.

Publisher's note Springer Nature remains neutral with regard to jurisdictional claims in published maps and institutional affiliations. 